\title{
ФОРМИРОВАНИЕ ГОСУДАРСТВЕННЫХ ФИНАНСОВЫХ РЕСУРСОВ В СУБЪЕКТЕ РОССИЙСКОЙ ФЕДЕРАЦИИ
}

\author{
(C) 2018 Шапошникова Эльвира Тимерзяновна \\ Самарский государственный экономический университет \\ 443090, г. Самара, ул. Советской Армии, д. 141 \\ E-mail: elvina1706@yandex.ru
}

В статье проведен анализ потоков государственных финансовых ресурсов в субъекте Российской Федерации (на примере Самарской области), проанализирована структура доходов, перечисленных в бюджеты бюджетной системы на территории Самарской области, в разрезе главных администраторов доходов, групп, подгрупп доходов, приведена динамика изменений поступлений в бюджеты различного уровня на территории Самарской области с 2013 по 2016 годы, рассмотрено соотношение отдельных видов налоговых и неналоговых доходов между поступлениями в доход федерального бюджета и бюджет Самарской области, особое внимание уделено межбюджетным трансфертам.

Ключевые слова: государственные финансовые ресурсы, федеральный бюджет, бюджет субъекта Российской Федерации, доходы федерального бюджета, доходы бюджета субъекта Российской Федерации, главный администратор доходов федерального бюджета, главный администратор доходов бюджета субъекта Российской Федерации, межбюджетные трансферты

Согласно принципам, заложенным в основу регулирования государственных финансовых ресурсов в федеративных государствах, субъекты федерации организуют и осуществляют регулирование финансов, переданных им, самостоятельно [5]. Устав Самарской области определяет, что бюджет области, местные бюджеты, бюджеты территориальных государственных внебюджетных фондов области являются финансовой основой области [4]. Вместе с тем в соответствии с принципами федерализма на территории субъекта федерации существуют еще как минимум два независимых от властей субъекта федерации финансовых потока. Во-первых, денежные средства центральных властей федерации и во-вторых, финансовые ресурсы, принадлежащие местным (муниципальным) властям. Данное утверждение подтверждается постановлением Конституционного Суда Российской Федерации, согласно которому федеральная власть, власть субъектов федерации, а также власть местного самоуправления имеют место быть на одной и той же территории, при этом полномочия их разграничены [3]. По нашему мнению уже на этом этапе возникает определённая юридическая коллизия. Дело в том, что существует другое определение Конституционного Суда Российской Федерации, согласно которому глава субъекта Российской Федерации отвечает за обеспечением Правительством субъекта федерации исполнения на его территории как конституции (устава), законов и иных нормативных правовых актов субъекта федерации, так и Конституции, федеральных законов и иных нормативных правовых актов Российской Федерации. По своему статусу это должностное лицо - в силу принципа единства системы государственной власти - находится в отношениях субординации непосредственно с Президентом Российской Федерации, который как глава государства, избираемый посредством всеобщих прямых выборов, обеспечивает согласованное функционирование всех органов государственной власти на основе взаимосвязанных положений статей 19 (части 1 и 2), 77 (часть 1), 78 (часть 4) и 80 (части 1 и 2) Конституции Российской Федерации [1]. Глава субъекта федерации принимает участие в отношениях не только касательно соответствующего субъекта федерации, но и Российской Федерации, при этом реализует как полномочия в пределах предметов совместного ведения Российской Федерации и субъектов федерации, так и в рамках исключительного ведения субъектов федерации [2]. То есть при наличии принципа разделения полномочий и обособленной сферы деятельности уровней власти глава субъекта выступает в качестве члена исполнительной власти федерации и имеет полномочия этой власти в субъекте федерации. Эта коллизия позволяет власти осуществлять манипуляции своими полномочиями в регионах.

Как же реализуются указанные правила на 
практике в Самарской области, как субъекте Российской Федерации с позиций финансового регулирования. С использованием казначейской технологии, в основу которой положена концепция единого казначейского счёта бюджета различного уровня, открытого органу Федерального казначейства в субъекте федерации, самостоятельно формируется доходы для каждого бюджета бюджетной системы. Рассмотрим поступления доходов в бюджеты различного уровня в Самарской области за период с 2013 по 2016 годы.

Всего в период с 2013 по 2016 годы перечислено в бюджеты бюджетной системы Российской Федерации в регионе 733,21 млрд. руб., в том числе в федеральный бюджет - 339,49 млрд. руб., в бюджет региона - 266,24 млрд. руб., в местные бюджеты - 127,48 млрд. руб. При этом необходимо отметить, что общая сумма перечислений в доходы бюджетов с 2013 года (339,32 млрд. руб.) по 2016 увеличилась на 54,57 млрд. руб. (или на $16,08 \%$ ) и составила 393,89 млрд. руб. Вместе с тем отмечается снижение поступлений в местные бюджеты с 64,9 млрд. руб. в 2013 году до 62,58 млрд. руб. или на 2,32 млрд. руб. (на 3,57\%) в 2016 и одновременное увеличение доходной части федерального бюджета на $24,23 \%$ с 151,4 млрд. руб. в 2013 году до 188,09 млрд. руб. в 2016 (на 36,69 млрд. руб.). Прирост поступлений в бюджет региона составляет $16,42 \%$ или на 20,2 млрд. руб. (в 2013 году - 123,02 млрд. руб., в 2016-143,22 млрд. руб.) или на том же уровне, что и рост перечислений в доходы бюджетной системы в целом по региону [6,7].

Таким образом, принимая во внимание принципы федерализма, органы управления регионом от года в год все меньше оказывают влияние на финансовую ситуацию, а финансовые потоки с каждым годом всё больше устремляются из региона в федеральный бюджет. В этой связи следует остановиться на структуре доходов, перечисленных в бюджеты различного уровня в Самарской области. Доля поступлений в федеральный бюджет с 2013 года увеличилась в 2016 на 3,1\%, при этом доля доходов местного бюджета сократилась на $3,2 \%$ и только совсем незначительно на $0,1 \%$ подросла доля перечислений в бюджет региона. Что подтверждает сделанный ранее вывод об ослабевающей роли властей региона.

Чтобы разобраться в сложившейся ситуации целесообразно проанализировать структуру поступлений доходов в федеральный бюджет и бюджет региона. В 2016 году в связи с различного рода реорганизациями исполнительной власти федерации в Самарской области количество главных администратора доходов федерального бюджета сократилось по сравнению с их числом в 2013 и составило 38 (в 2013-44). Общая сумма всех доходов, поступающих от реорганизованных главных администраторов, в поступлениях в федеральный бюджет составляла $1,2 \%$. Самая большая доля собираемых платежей в федеральный бюджет приходится на Федеральную налоговую службу и Федеральное казначейство (в 2016 году - 5\% от общего числа администраторов): Федеральная налоговая служба (от 90\% в 2013 году до 92\% в 2016) и Федеральное казначейство (от 5\% в 2013 году до 6\% в 2016). На оставшихся 95\% администраторов доходов приходится 3-5\% доходов федерального бюджета (табл. 1).

Таблица 1. Структура поступлений в доход федерального бюджета на территории Самарской области в 2013-2016 годах в разрезе главных администраторов доходов федерального бюджета [6]

\begin{tabular}{|c|c|c|c|c|c|}
\hline \multirow{2}{*}{$\begin{array}{c}\text { № } \\
\text { п/п }\end{array}$} & $\begin{array}{c}\text { Наименование главного администратора дохо- } \\
\text { дов федерального бюджета }\end{array}$ & $\begin{array}{c}\text { Суммы } \\
\text { доходов } \\
\text { (млн. руб.) }\end{array}$ & $\begin{array}{c}\text { Суммы } \\
\text { доходов } \\
\text { (млн. руб.) }\end{array}$ & $\begin{array}{c}\text { Изменение } \\
2016-2013 \\
(\text { млн. руб.) }\end{array}$ & $\begin{array}{c}\text { Изменение } \\
2016 / 2013 \\
(\%)\end{array}$ \\
\hline 1 & 2 & 3 & 4 & 5 & 6 \\
\hline 1 & Министерство промышленности и торговли РФ & 0,90 & 0,50 & $-0,40$ & 55,8 \\
\hline 2 & Министерство энергетики РФ & 272,55 & 28,44 & -244.11 & 34,2 \\
\hline 3 & Федеральная служба по надзору в сфере приро- \\
допользования & 154,09 & 52,71 & $-101,38$ & 34,2 \\
\hline 4 & Федеральное агентство по недропользованию & 1311,90 & & & \\
\hline 5 & Федеральное агентство водных ресурсов & 3,45 & 5,79 & 2,34 & 167,9 \\
\hline 6 & Федеральное агентство лесного хозяйства & 52,29 & 42,48 & $-9,81$ & 81,2 \\
\hline 7 & Федеральная служба по надзору в сфере здраво- & 3,09 & 5,45 & 2,36 & 176,5 \\
\hline
\end{tabular}




\begin{tabular}{|c|c|c|c|c|c|}
\hline 8 & Федеральное агентство по рыболовству & 0,83 & 3,51 & 2,68 & 422,5 \\
\hline 9 & $\begin{array}{c}\text { Федеральная служба по надзору в сфере образо- } \\
\text { вания и науки }\end{array}$ & 0,36 & 0,91 & 0,55 & 251,6 \\
\hline 10 & $\begin{array}{c}\text { Федеральная служба по ветеринарному и фито- } \\
\text { санитарному надзору }\end{array}$ & 0,21 & 3,14 & 2,93 & 1494,5 \\
\hline 11 & Государственная фельдъегерская служба РФ & 3,98 & 3,73 & $-0,25$ & 93,7 \\
\hline 12 & $\begin{array}{c}\text { Федеральная служба по надзору в сфере связи, } \\
\text { информационных технологий и массовых ком- } \\
\text { муникаций }\end{array}$ & 0,62 & 0,68 & 0,06 & 110,0 \\
\hline 13 & Федеральное казначейство & 7164,88 & 11634,77 & 4469,89 & 162,4 \\
\hline 14 & $\begin{array}{c}\text { Федеральная служба по надзору в сфере } \\
\text { транспорта }\end{array}$ & 12,25 & 28,85 & 16,60 & 235,5 \\
\hline 15 & Федеральное агентство воздушного транспорта & 0,82 & 2,42 & 1,60 & 295,1 \\
\hline \multirow[t]{2}{*}{16} & $\begin{array}{c}\text { Федеральная служба по надзору в сфере защиты } \\
\text { прав потребителей и благополучия человека }\end{array}$ & 0,99 & 14,68 & 13,69 & 1482,5 \\
\hline & Министерство труда и социальной защиты & & & & \\
\hline 17 & Федеральная служба по труду и занятости & 15,12 & 66,20 & 51,08 & 437,8 \\
\hline 18 & $\begin{array}{c}\text { Федеральная служба финансово-бюджетного } \\
\text { надзора }\end{array}$ & 11,48 & & & \\
\hline 19 & Федеральная таможенная служба & 1,41 & 1,21 & $-0,20$ & 86,0 \\
\hline 20 & Федеральное архивное агентство & 12,92 & 19,84 & 6,92 & 153,5 \\
\hline 21 & Федеральная служба государственной статистики & 12,00 & 12,31 & 0,31 & 102,6 \\
\hline 22 & Федеральная антимонопольная служба & 16,58 & 6,11 & $-10,47$ & 36,8 \\
\hline 23 & $\begin{array}{c}\text { Федеральное агентство по управлению государ- } \\
\text { ственным имуществом }\end{array}$ & 856,76 & 717,21 & $-139,55$ & 83,7 \\
\hline 24 & $\begin{array}{c}\text { Федеральное агентство по государственным } \\
\text { резервам }\end{array}$ & 15,94 & 38,28 & 22,34 & 240,2 \\
\hline 25 & $\begin{array}{c}\text { Министерство РФ по делам гражданской обо- } \\
\text { роны, чрезвычайным ситуациям и ликвидации } \\
\text { последствий стихийных бедствий }\end{array}$ & 337,57 & 250,58 & $-86,99$ & 74,2 \\
\hline 26 & Федеральная налоговая служба & 137583,26 & 172221,59 & 34638,33 & 123,2 \\
\hline 27 & Федеральная служба по оборонному заказу & 0,49 & & & \\
\hline 28 & Министерство обороны РФ & 253,46 & 139,76 & $-113,70$ & 55,1 \\
\hline 29 & Министерство внутренних дел РФ & 1239,64 & 1313,67 & 74,03 & 106,0 \\
\hline 30 & Федеральная служба безопасности РФ & 9,08 & 11,03 & 1,95 & 121,4 \\
\hline 31 & Федеральная миграционная служба & 453,33 & & & \\
\hline 32 & Федеральная служба охраны РФ & 7,45 & 6,02 & $-1,43$ & 80,9 \\
\hline 33 & $\begin{array}{c}\text { Федеральная служба РФ по контролю за оборо- } \\
\text { том наркотиков }\end{array}$ & 7,47 & & & \\
\hline 34 & Министерство иностранных дел РФ & 0,08 & 0,02 & $-0,06$ & 25,0 \\
\hline 35 & Министерство юстиции РФ & 40,09 & 55,36 & 15,27 & 138,1 \\
\hline 36 & Федеральная служба исполнения наказаний & 725,25 & 666,69 & $-58,56$ & 91,0 \\
\hline 37 & $\begin{array}{c}\text { Федеральная служба государственной регистра- } \\
\text { ции, кадастра и картографии }\end{array}$ & 634,81 & 483,71 & $-151,10$ & 76,2 \\
\hline 38 & Федеральная служба судебных приставов & 154,06 & 192,89 & 38,83 & 125,2 \\
\hline 39 & Генеральная прокуратура РФ & 3,68 & 6,38 & 2,70 & 173,5 \\
\hline 40 & Следственный комитет РФ & 1,68 & 2,61 & 0,93 & 155,6 \\
\hline 41 & Высший Арбитражный Суд РФ & 1,26 & & & \\
\hline 42 & Судебный департамент при Верховном Суде РФ & 1,49 & 0,85 & $-0,64$ & 57,3 \\
\hline 43 & $\begin{array}{c}\text { Федеральная служба по экологическому, техно- } \\
\text { логическому и атомному надзору }\end{array}$ & 12,13 & 35,30 & 23,17 & 291,0 \\
\hline \multirow[t]{2}{*}{44} & Центральный банк РФ & 34,90 & 12,92 & $-21,98$ & 37,0 \\
\hline & ИТОГо: & 151426,60 & 188088,62 & 36662,02 & 124,2 \\
\hline
\end{tabular}


Анализируя структуру поступлений по видам доходов федерального бюджета, можно отметить, что основу доходов федерального бюджета, поступивших на территории Самарской области, составляют налоговые доходы (84,9\% от общей суммы доходов (188088,62 млн. руб.) или 159775,86 млн. руб. в 2016 году), а именно 2 вида доходов из 17 видов доходов, собираемых на территории субъекта Российской Федерации: налоги на товары (работы, услуги), реализуемые на территории Российской Федерации (41,9\% от общей суммы доходов или 78821,71 млн. руб. в 2016 году) и налоги, сборы и регулярные платежи за пользование природными ресурсами (39,7\% от общей суммы доходов или 74733,31 млн. руб.). При этом именно эти виды доходов показывают положительную динамику поступлений. Так в 2016 году налогов на товары (работы, услуги), реализуемые на территории Российской Федерации, было собрано на $10,3 \%$ больше, чем в 2013, а налогов, сборов и регулярных платежей за пользование природными ресурсами - на 23,5\%, что дало прирост налоговых поступлений в целом более чем на 16\%. Из неналоговых доходов заметную роль в 2016 году стали играть поступления от платежей при пользовании природными ресурсами. Если в 2013 году их доля в общей сумме доходов едва дотягивала до 1\% (1 504,1 млн. руб.), то 2016 она возросла до $6,4 \%$, а сумма поступлений выросла более чем в 8 раз и составила 12 127,62 млн. руб.). Около 1\% колеблется доля поступлений от оказания платных услуг государством (990,05 млн. руб. в 2016 году) и сумм от государственной пошлины (1778,67 млн. руб. в 2016 году), хотя они показывают отрицательную динамику [6].

Резюмируя, можно сделать вывод, что налоги за пользование природными ресурсами и косвенные налоги составляют основу доходов федерального бюджета, собираемых в регионе. Данные виды налогов в наименьшей степени зависят от уровня инфляции в стране. Поэтому, несмотря на то, что в период с 2013 по 2016 годы в экономике страны отметилась тенденция к стагнации, доходы федерального бюджета за исследуемый период выросли на 24,2\%. Напомним, что и в СССР аналогичный этим доходам налог с оборота давал положительную динамику при ухудшающихся экономических условиях последних лет существования страны.

Рассмотрев структуру поступлений в доход федерального бюджета, необходимо также про- анализировать структуру поступлений в доход бюджета Самарской области. На территории региона согласно закону о бюджете Самарской области функционирует 50 главных администраторов доходов бюджета региона. При этом территориальные органы федеральных органов исполнительной власти составляют 36\% (18). Наибольший доход в бюджет региона приносят Управление федеральной налоговой службы по Самарской области - 92,2\% в 2013 году и 78\% в 2016 и Управление Федерального казначейства по Самарской области - 5,5\% в 2013 году и 5,7\% в 2016. 83\% доходов бюджета области приходятся на 4\% главных администраторов доходов. За ними следуют Главное управление внутренних дел по Самарской области (доля доходов в 2016 году достигла почти 1\%) и Управление Роприроднадзора по Самарской области - 0,2\%. Обращает на себя внимание, что это всё территориальные подразделения центральных властей страны. Они дают субъекту около 99\% доходов. Из органов исполнительной власти региона можно выделить Министерство имущественных отношений, в 2016 году доля доходов составляла $0,14 \%$, снизившись за исследуемый период на 0,13\%, и Министерство управления финансами Самарской области, доля администрируемых им доходов в 2016 году составила 0,5\% (табл. 2).

По аналогии с федеральным бюджетом в 2016 году, налоговые доходы $(83,1 \%$ или 118971,46 млн. руб., в федеральном бюджете $84,9 \%$ ) составляют основу в структуре доходов бюджета региона. При этом на налоги на прибыль приходится 54,2\% (или 77 644,77 млн. руб., в федеральном бюджете - 2,7\%). Далее следуют налоги на товары (работы, услуги), реализуемые на территории Российской Федерации $(13,7 \%$ или 19616,56 млн. руб., в федеральном бюджете $-41,9 \%)$. Сразу за этой группой доходов в нашем условном рейтинге, идут налоги на имущество (11,9\% или 16987,05 млн. руб.), налоги на совокупный доход (3,3\% или 4666,34 млн. руб.) и наконец, налоги за пользование природными ресурсами $(0,04 \%$ или 56,74 млн. руб., при этом в федеральном бюджете - 40\%) [6,7]. Таким образом, в федеральный бюджет поступают практически все доходы от пользования природных ресурсов области.

Весомую долю в общей сумме доходов региона составляют межбюджетные трансферты (15\%). При этом незначительное снижение доли межбюджетных трансфертов в 2016 году по срав- 
Таблица 2. Структура поступлений в доход бюджета Самарской области в 2013-2016 годах в разрезе главных администраторов доходов бюджета субъекта Российской Федерации [6,7]

\begin{tabular}{|c|c|c|c|c|c|}
\hline \multirow[b]{2}{*}{$\begin{array}{l}\text { № } \\
\text { П/ח }\end{array}$} & \multirow[b]{2}{*}{ Наименование администратора } & 2013 & 2016 & \multirow[b]{2}{*}{$\begin{array}{l}\text { Изменение } \\
2016-2013 \\
\text { (млн. руб.) }\end{array}$} & \multirow[b]{2}{*}{$\begin{array}{l}\text { Изменение } \\
\text { 2016/2013 } \\
\text { (\%) }\end{array}$} \\
\hline & & $\begin{array}{c}\text { Суммы } \\
\text { доходов } \\
\text { (млн. руб.) }\end{array}$ & $\begin{array}{c}\text { Суммы } \\
\text { доходов } \\
\text { (млн. руб.) }\end{array}$ & & \\
\hline 1 & 2 & 3 & 4 & 5 & 6 \\
\hline 1 & $\begin{array}{c}\text { Управление Федеральной службы по надзору в } \\
\text { сфере природопользования (Росприроднадзора) по } \\
\text { Самарской области }\end{array}$ & 292,10 & 270,49 & $-21,61$ & 92,6 \\
\hline 2 & Федеральное агентство лесного хозяйства & 0,15 & 0,75 & 0,60 & 500 \\
\hline 3 & $\begin{array}{c}\text { Средневолжское территориальное управление Фе- } \\
\text { дерального агентства по рыболовству }\end{array}$ & & & & \\
\hline 4 & $\begin{array}{c}\text { Управление Федеральной службы по ветеринар- } \\
\text { ному и фитосанитарному надзору по Самарской } \\
\text { области }\end{array}$ & & & & \\
\hline 5 & $\begin{array}{c}\text { Управление Федеральной службы по надзору в сфе- } \\
\text { ре связи, информационных технологий и массовых } \\
\text { коммуникаций по Самарской области }\end{array}$ & 0,40 & 0,35 & $-0,05$ & 87,3 \\
\hline 6 & $\begin{array}{c}\text { Управление Федерального казначейства по Смо- } \\
\text { ленской области (с } 2014 \text { года по Самарской области) }\end{array}$ & 5680,26 & 8107,24 & 2426,98 & 142,7 \\
\hline 7 & $\begin{array}{c}\text { Управление Федеральной службы по надзору в сфе- } \\
\text { ре транспорта по Самарской области }\end{array}$ & 0,15 & 1,42 & 1,27 & 944,7 \\
\hline 8 & $\begin{array}{c}\text { Управление Федеральной службы по надзору в } \\
\text { сфере защиты прав потребителей и благополучия } \\
\text { человека по Самарской области }\end{array}$ & 5,34 & 2,55 & $-2,79$ & 47,8 \\
\hline 9 & $\begin{array}{c}\text { Управление Федеральной антимонопольной служ- } \\
\text { бы по Самарской области }\end{array}$ & 1,16 & 1,18 & 0,02 & 101,8 \\
\hline 10 & $\begin{array}{c}\text { Главное управление Министерства Российской } \\
\text { Федерации по делам гражданской обороны, чрез- } \\
\text { вычайным ситуациям и ликвидации последствий } \\
\text { стихийных бедствий по Самарской области }\end{array}$ & 44,74 & 16,4 & $-28,3$ & 36,7 \\
\hline 11 & $\begin{array}{c}\text { Управление Федеральной налоговой службы по } \\
\text { Самарской области }\end{array}$ & 95600,57 & 110876,15 & 15273,58 & 116 \\
\hline 12 & Министерство обороны Российской Федерации & 0,04 & 0,09 & 0,05 & 220 \\
\hline 13 & $\begin{array}{c}\text { Главное управление Министерства внутренних дел } \\
\text { Российской Федерации по Самарской области }\end{array}$ & 556,78 & 1409,25 & 852,47 & 253,1 \\
\hline 14 & $\begin{array}{c}\text { Управление Федеральной миграционной службы по } \\
\text { Самарской области }\end{array}$ & & & & \\
\hline 15 & $\begin{array}{c}\text { Управление Министерства юстиции Российской } \\
\text { Федерации по Самарской области }\end{array}$ & 0,94 & 0,52 & $-0,42$ & 55,6 \\
\hline 16 & $\begin{array}{c}\text { Управление Федеральной службы судебных приста- } \\
\text { вов по Самарской области }\end{array}$ & 0,34 & 0,71 & 0,37 & 208,2 \\
\hline 17 & Генеральная прокуратура РФ & 0,61 & 1,62 & 1,01 & 265,1 \\
\hline 18 & $\begin{array}{c}\text { Управление по технологическому и экологическому } \\
\text { надзору Федеральной службы по экологическому, } \\
\text { технологическому и атомному надзору по Самар- } \\
\text { ской области }\end{array}$ & & & & \\
\hline 19 & Самарская Губернская Дума & 1,75 & 0,37 & $-1,39$ & 20,9 \\
\hline 20 & $\begin{array}{c}\text { Представительство Правительства Самарской обла- } \\
\text { сти при Правительстве Российской Федерации }\end{array}$ & 11,08 & 0,92 & $-10,16$ & 8,3 \\
\hline 21 & $\begin{array}{c}\text { Министерство экономического развития, инвести- } \\
\text { ций и торговли Самарской области }\end{array}$ & 73,74 & 72,29 & $-1,45$ & 98 \\
\hline 22 & $\begin{array}{c}\text { Министерство имущественных отношений Самар- } \\
\text { ской области }\end{array}$ & 332,46 & 193,96 & $-138,5$ & 58,3 \\
\hline 23 & $\begin{array}{c}\text { Министерство транспорта и автомобильных дорог } \\
\text { Самарской области }\end{array}$ & 84,21 & 143,26 & 59,05 & 170,1 \\
\hline
\end{tabular}




\begin{tabular}{|c|c|c|c|c|c|}
\hline 24 & $\begin{array}{l}\text { Министерство сельского хозяйства и продоволь- } \\
\text { ствия Самарской области }\end{array}$ & 1,21 & 1,08 & $-0,13$ & 89,3 \\
\hline 25 & Министерство здравоохранения Самарской области & 36,53 & 59,84 & 23,31 & 163,8 \\
\hline 26 & $\begin{array}{c}\text { Министерство промышленности и технологий } \\
\text { Самарской области }\end{array}$ & 0,21 & 0,30 & 0,09 & 144,3 \\
\hline 27 & $\begin{array}{c}\text { Министерство образования и науки Самарской } \\
\text { области }\end{array}$ & 6,81 & 8,62 & 1,81 & 126,5 \\
\hline 28 & Министерство культуры Самарской области & 2,61 & & $-2,61$ & 0 \\
\hline 29 & Министерство строительства Самарской области & 100,17 & 70,99 & $-29,18$ & 70,9 \\
\hline 30 & Министерство спорта Самарской области & 0,04 & 0,10 & 0,06 & 237,5 \\
\hline 31 & $\begin{array}{c}\text { Департамент информационных технологий и связи } \\
\text { Самарской области }\end{array}$ & 1,74 & 3,25 & 1,51 & 186,8 \\
\hline 32 & Служба мировых судей Самарской области & 1,69 & 0,16 & $-1,53$ & 9,5 \\
\hline 33 & $\begin{array}{c}\text { Министерство энергетики и жилищно-коммуналь- } \\
\text { ного хозяйства Самарской области }\end{array}$ & 0,48 & 0,41 & $-0,07$ & 84,8 \\
\hline 34 & $\begin{array}{c}\text { Министерство труда, занятости и миграционной } \\
\text { политики Самарской области }\end{array}$ & 20,05 & 12,31 & $-7,74$ & 61,4 \\
\hline 35 & $\begin{array}{c}\text { Департамент управления делами Губернатора } \\
\text { Самарской области и Правительства Самарской } \\
\text { области }\end{array}$ & 38,38 & 31,14 & $-7,24$ & 81,1 \\
\hline 36 & $\begin{array}{c}\text { Главное управление организации торгов Самарской } \\
\text { области }\end{array}$ & 0,23 & 0,21 & $-0,02$ & 90 \\
\hline 37 & $\begin{array}{c}\text { Департамент охоты и рыболовства Самарской } \\
\text { области }\end{array}$ & 0,90 & 1,18 & 0,28 & 131,3 \\
\hline 38 & Избирательная комиссия Самарской области & 0,001 & 0,008 & 0,007 & 800 \\
\hline \multirow[t]{2}{*}{39} & $\begin{array}{l}\text { Уполномоченный по правам человека в Самарской } \\
\text { области }\end{array}$ & 4,23 & & & \\
\hline & $\begin{array}{c}\text { Департамент по вопросам общественной безопас- } \\
\text { ности Самарской области }\end{array}$ & & 4,24 & $-0,02$ & 99,5 \\
\hline 40 & $\begin{array}{c}\text { Государственная инспекция по надзору за техни- } \\
\text { ческим состоянием самоходных машин и других } \\
\text { видов техники Самарской области }\end{array}$ & 30,08 & 33,68 & 3,60 & 112 \\
\hline 41 & $\begin{array}{c}\text { Управление записи актов гражданского состояния } \\
\text { Самарской области }\end{array}$ & 0,01 & 0,08 & 0,07 & 800 \\
\hline 42 & $\begin{array}{c}\text { Государственная инспекция строительного надзора } \\
\text { Самарской области } \\
\end{array}$ & & & & \\
\hline 43 & $\begin{array}{l}\text { Управление государственной архивной службы } \\
\text { Самарской области }\end{array}$ & & 0,003 & 0,003 & 100 \\
\hline 44 & $\begin{array}{c}\text { Государственная жилищная инспекция Самарской } \\
\text { области }\end{array}$ & 0,03 & 2,75 & 2,72 & 9160 \\
\hline 45. & Счетная палата Самарской области & 0,01 & 0,05 & 0,04 & 450 \\
\hline 46. & Департамент ветеринарии Самарской области & 0,02 & 0,23 & 0,21 & 1165 \\
\hline 47 & $\begin{array}{c}\text { Министерство социально-демографической и се- } \\
\text { мейной политики Самарской области }\end{array}$ & 3,48 & 6,74 & 3,26 & 193 \\
\hline 48. & $\begin{array}{c}\text { Управление государственной охраны объектов } \\
\text { культурного наследия Самарской области }\end{array}$ & & 0,1 & 0,1 & 100 \\
\hline 49. & $\begin{array}{c}\text { Министерство управления финансами Самарской } \\
\text { области }\end{array}$ & 524,19 & 629,66 & 105,47 & 120,1 \\
\hline \multirow[t]{4}{*}{50.} & $\begin{array}{c}\text { Министерство лесного хозяйства, охраны окру- } \\
\text { жающей среды и природопользования Самарской } \\
\text { области }\end{array}$ & 41,40 & 44,42 & 3,02 & 107,3 \\
\hline & Всего налоговых и неналоговых доходов & 103684,22 & 122009,06 & 18324,81 & 117,7 \\
\hline & Безвозмездные поступления & 20023,20 & 21210,34 & 1187,14 & 105,9 \\
\hline & ИТОГо: & 123707,42 & 143219,39 & 19511,95 & 115,8 \\
\hline
\end{tabular}


нению с 2013 на 1,4\% или на 1187,13 млн. руб. вызвано снижением доли дотаций в 2016 году по сравнению с 2013 на 1,28\% или на 1518,32 млн. руб., а также сокращением доли субсидий на 1,31\% или на 601,1 млн. руб. при незначительном росте субвенций на 0,17\% или на 1201,96 млн. руб. [6,7]. Проведенный анализ подтверждает, что власти региона стараются вовлечь федеральные власти к сотрудничеству как в рамках софинансирования, так и в рамках передачи отдельных властных полномочий на уровень субъекта. Хотя рост сумм доходов от субвенций (на 18,6\%) вряд ли сможет оказать заметное влияние на общую доходность Самарской области.

В общей сумме доходов неналоговые доходы в 2016 году составляют 2,1\% или 3037,6 млн. руб. (доля их в федеральном бюджете в 2016 году по сравнению с 2013 (4\%) увеличилась до 8\%). Как объект управления доходами органами власти региона это наиболее доступный элемент. Ощутимое значение в этой группе доходов имеют штрафы, санкции, доля которых возросла в 2,1 раза и составила в 2016 году почти 1,1\% в общей сумме доходов или 1591,11 млн. руб. (в доходах федерального бюджета 0,2\%) и доходы от использования имущества, в 2016 году их доля снизилась по сравнению с 2013 (0,8\%) до 0,6\% и составила 799,39 млн. руб. (в федеральном бюджете - 0,5\%). Доля платежей за пользование природными ресурсами в 2016 году составила всего 0,2\% или 318,88 млн. руб. (при этом в федеральном бюджете - 6,4\%).

Проанализировав соотношение налоговых и неналоговых доходов между потоками в федеральный бюджет и бюджет области, можно сделать вывод, что Самарская область богата полезными ископаемыми, но практически все платежи от пользования природными ресурсами уходят в федеральный бюджет (99\% налога и 95\% иных платежей). Проведенный анализ показывает, что для успешного регулирования процессами формирования финансовых ресурсов Самарской области, в создавшейся системе собственных доходов бюджета субъекта Российской Федерации необходимо, чтобы органы управления осуществляли поддержку крупных предприятий, малого и среднего бизнеса, в том числе сельхозтоваропроизводителей - плательщиков налогов, развивали систему предоставления государственных услуг. Также необходимо активнее привлекать правительство страны в процессы софинансирования, учитывая, что возвращается в область только 14\% в виде межбюджетных трансфертов.

\section{Библиографический список}

1. Конституция Российской Федерации: принята всенародным голосованием 12.12.1993. - Электрон. текстовые дан.- Режим доступа: http://www.consultant.ru/popular/cons/ (дата обращения: 21.06.2018). - Загл. с экрана.

2. Постановление Конституционного Суда Российской Федерации от 14.07.1997 № 12-П «По делу о толковании содержащегося в части 4 статьи 66 Конституции Российской Федерации положения о вхождении автономного округа в состав края, области».- Электрон. текстовые дан.-Режим доступа: http://base.consultant. ru/cons/cgi/online.cgi?req=doc; base=LAW; n=15235 (дата обращения: 16.06.2018). - Загл. с экрана.

3. Постановление Конституционного Суда Российской Федерации от 21.12.2005 N13-П «По делу о проверке конституционности отдельных положений Федерального закона «Об общих принципах организации законодательных (представительных) и исполнительных органов государственной власти субъектов Российской Федерации» в связи с жалобами ряда граждан».- Электрон. текстовые дан.- Режим доступа: http://base.consultant.ru/cons/cgi/online.cgi?req=doc; base=LAW; n=57388 (дата обращения: 16.01.2015).Загл. с экрана.

4. Устав Самарской области / Правительство Самарской области, официальный сайт.- Электрон. текстовые дан.- Режим доступа: http://www.samregion.ru/documents/rules (дата обращения: 23.06.2018).- Загл. с экрана.

5. Валиева Е.Н. Государственные (муниципальные) финансы: учебное пособие / Е.Н. Валиева, А.Г. Лукин. Москва. 2018.-144 с. - (Серия «Магистратура»).

6. Информация о распределении доходов по уровням бюджетов бюджетной системы Российской Федерации по состоянию на 01.01.2014 и 01.01.2015 / Официальный сайт Управления Федерального казначейства по Самарской области. Раздел «Информация об исполнении бюджетов».- Электрон. текстовые дан.- Режим доступа: http://old.samara.roskazna.ru/page/24660 (дата обращения: 18.10.2015).- Загл. с экрана. 
7. Отчет об исполнении бюджета Самарской области за 2015 и 2016 гг. / Официальный сайт Министерства управления финансами Самарской обл., раздел «Отчёты об исполнении бюджета»,- Электрон. текст. данные.- Режим доступа http://minfin-samara.ru/reports-on-the-budget. (дата обращения 22.10.2017)._- Загл. с экрана.

Поступила в редакцию 27.08.2018 